\title{
Restos audibles: \\ entre la poesía y la historia en Punctum, de Martín Gambarotta
}

Mario Cámara

Universidad de Buenos Aires - CONICET

\begin{abstract}
Resumen
El presente artículo se focaliza en el poemario Punctum (1996) de Martín Gambarotta, a efectos de analizar allí la construcción de un discurso poético que trabaja tanto con un régimen poético basado en la materialidad del significante, como con un régimen que procura escuchar y hacer audibles los restos de la historia reciente de Argentina, centrándose especialmente en la historia de la militancia política y las organizaciones armadas de los años setenta.
\end{abstract}

Palabras clave: materialidad; historia reciente; restos

\begin{abstract}
This article focuses on the poems Punctum (1996) by Martin Gambarotta, in order to analyze the construction of a poetic discourse that works with poetic regime based on the materiality of the signifier, as with a regime that seeks to listen and make audible the remains of Argentina's recent history, particularly focusing on the history of political activism and armed organizations of the seventies.
\end{abstract}

Keys words: materiality; recent history; remains 
1. DOBRY, Edgardo. "Poesía argentina actual: del neobarroco al objetivismo. (y más allá)", 2006, p. 121.

2. Daniel García Helder, apud. PRIETO, Martín. Breve historia de la literatura argentina, 2006, p. 452.
Sombra terrible de Facundo, voy a evocarte, para que, sacudiendo el ensangrentado polvo que cubre tus cenizas, te levantes a explicarnos la vida secreta y las convulsiones internas que desgarran las entrañas de un noble pueblo.

Domingo Faustino Sarmiento

En 1995, el libro de poemas del joven Martín Gambarotta, Punctum, obtuvo el primer premio del Diario de Poesía y desató una inmediata controversia en torno a su valoración. Pese a las polémicas iniciales, el premio recibido representaba la consolidación y la renovación de un movimiento poético, el objetivismo, que en Argentina había comenzado a tornarse visible desde la segunda mitad de los años ochenta como respuesta a lo que Edgardo Dobry llama "los últimos coletazos de la vanguardia en el Río de la Plata"1, refiriéndose con ello al neobarroco. El punto de partida para el objetivismo había sido el texto de Daniel García Helder, "El neobarroco en la Argentina”, publicado en 1987 en el cuarto número del Diario de Poesía, que proponía oponer al lujo léxico del neobarroco un diccionario restringido, y a la indeterminación del sentido un máximo de sentido. El objetivismo debía ser una poesía "arriesgada en su tarea de lograr algún tipo de belleza mediante la precisión, lo breve, la fácil o difícil claridad”2.

Sin embargo, entre los inicios del objetivismo, o sea entre Daniel García Helder, Rafael Bielsa, Daniel Freidemberg y Jorge Fondebrider, y Martín Gambarotta, y algunos de los que pueden ser considerados sus compañeros de generación, como Juan Desiderio o Alejandro Rubio, por citar sólo dos, se produjeron notables diferencias. Si en su escrito fundacional, García Helder apelaba a Pound para proponer un lenguaje cargado de sentido, en los más jóvenes parecía haber un rechazo de todo lo que "oliera" a literatura; si para los primeros el neobarroco era el movimiento a superar, para esta nueva generación el neobarroco no sólo había dejado de ser el otro bando, sino que simplemente había dejado de ser.

Resulta interesante recuperar la charla que Gambarotta ofrece en agosto de 2004 en el Centro Cultural de España, cuyo título es "El habla como materia prima", como un modo de entender la nueva ubicación que estos jóvenes - el propio Gambarotta, Desiderio, Rubio - pretendían para sí. Al narrar sus orígenes como escritor, Gambarotta se refiere a la novela Glosa de Juan José Saer - de quien, según sus palabras, ya había leído y admirado El limonero real, Cicatrices, Nadie nada 
nunca y La mayor -, y lo hace para afirmar que el personaje central, Ángel Leto, se le había hecho "un tanto lejano, un tanto ridículo y afectado”, a lo que añadía:

A la vez, la estructura se me hacía demasiado artificial. Y el problema que yo tenía también, cuando lo leía, era que evidentemente ésta era una novela política, un tema que en ese momento me interesaba mucho, y es la justificación que encuentro al hecho de haberme abierto a esta discusión tan animada con este libro 4 .

Concluyendo que “el 'fracaso' de Glosa me permitió vislumbrar como lector lo que me parecía que era el punto de una nueva literatura argentina" 5 . Recordemos que Glosa, publicada en 1985, narra una caminata compartida entre Ángel Leto y el Matemático durante sesenta minutos y veintiún cuadras en 1961, en la que el Matemático le cuenta la fiesta de cumpleaños de Washington Noriega, que a su vez le había sido contada, días antes, por Botón, a quien Leto no conoce en persona. En esa misma caminata, en un momento dado, se sumará Tomatis, que narrará su propia versión del cumpleaños. Poco antes de la culminación de la historia se nos hace saber el futuro militante de Ángel Leto, o más bien su fracaso ${ }^{6}$, y la muerte autoinflingida por la ingestión de una cápsula de arsénico, y obligada por una emboscada militar, durante la última dictadura.

No resulta sencillo detectar por qué el personaje de Ángel Leto le suena a Gambarotta "lejano", "ridículo" y "afectado", ni tampoco saber por qué la estructura se le presenta como artificial. Tal vez debamos buscar una explicación en el sistema de consagración crítica que se había ido construyendo en torno a la literatura de Saer. En este sentido, los nombres de María Teresa Gramuglio y Beatriz Sarlo resultan indispensables. Muy tempranamente - en la revista Los libros de septiembre de 1969 - María Teresa Gramuglio publica un texto sobre Cicatrices de Saer, que había sido editado ese mismo año, en el que sostenía:

La técnica narrativa de Cicatrices [...] parece ceñirse a los recursos tradicionales: por algo ya se ha hablado, a propósito de Responso, del clasicismo narrativo de Saer. Son los signos de la novela, en el sentido que Barthes los señala, en el sentido que algunos narradores contemporáneos se empeñan justamente en denunciar y destruir, los que Saer elige consciente y deliberadamente para construir $C^{-}$catrices. Nada más lejos de su intención que proponer la destrucción o el aniquilamiento de esos signos. Por el contrario, justamente a partir de la reivindicación de la escritura novelística, a partir de un obstinado empecinamiento en adherir a esos signos con una fidelidad que llega a la exasperación a partir, en suma, de la creencia en el poder de la palabra... ${ }^{7}$
3. GAMBAROTTA, Martín.

"El habla como materia prima", 2006, p. 238.

4. Ibidem., p. 238.

5. Ibidem, p. 238.

6. Sobre su militancia, Leto piensa lo siguiente: "Habiéndose dado cuenta al cabo de quince años que luchar a ciegas contra la opresión puede engendrar más opresión en lugar de acabar con ella, del mismo modo que ciertos métodos para combatir un incendio contribuyen más bien a acrecentar la fuerza de las llamas, y habiendo llegado demasiado lejos como para dar marcha atrás, empezará a confiar, no en estrategias, ni en organizaciones, ni en sacudimientos históricos, como los llaman, ni siquiera en su propia ametralladora, sino únicamente en la pastilla, en su pastilla, como quien podría decir, como se dice, en su sexto sentido o en su buena estrella" (SAER, Juan José. Glosa, 1995, pp. 270-271)

7. GRAMUGLIO, Maria Teresa. "Las aventuras del orden”, 1969, Buenos Aires. 
8. Idem, “juan José Saer: el arte de narrar”, 1977, p. 8. Refiriéndose a El entenado, Gramuglio vuelve a reafirmar el poder de la escritura, de un modo semejante a como lo había hecho en 1969: "Y de cómo la escritura, esa 'máquina de engaños', puede tender sobre el abismo su irrefutable y a la vez incierto puente de signos, para oponerse a tanta precariedad, a tanta incertidumbre, $y$, también, a la muerte" ("La filosofía en el relato. Sobre 'El entenado' de Juan José Saer” 1984, p. 36).

9. SARLO, Beatriz. "La condición mortal”, 1993, pp. 29-30.

10. GAMBAROTTA, Martín. "El habla como materia prima", 2006, pp. 238-9.

11. Ciertamente la de Hendrix no es una historia de fracasos. Es, sin duda, el guitarrista más innovador de su época y quizás de toda la historia del rock. La trayectoria de Hendrix durante 1967 es de un vertiginoso ascenso. A fines del año anterior - en octubre - conforma su grupo The Jimi Hendrix Experience, con el que debuta en Evreux, Francia. Basándose en el trémolo, algo completamente olvidado por los guitarristas posteriores a Hank Marvin, Hendrix da forma y dimensión a cada configuración de feedback, de distorsiones sonoras y de sonidos electrónicos puros, llegando a subir los cursores del amplificador muy por encima del nivel máximo que los fabricantes habían previsto. Toca la guitarra poniéndosela en la espalda, entre las piernas, usando los dientes, frotándola contra la caja de los amplificadores, contra el largo pie del micrófono y muchas veces, cuando está aburrido de estos juegos, termina rompiendo el instrumento en mil pedazos, prendiéndole fuego... o ambas cosas.

El 31 de marzo el grupo inicia una gira de 25 días por Gran Bretaña. Se trataba de conciertos "package", ya que el programa de cada velada preveía la ac-
Funda, de este modo, una orientación en la apreciación crítica - que se sostendrá en el tiempo - que destaca el poder de la palabra y la excelencia formal. Algunos años más tarde le sumará, desde las páginas de la revista Punto de Vista, el ensayo titulado "Juan José Saer: el arte de narrar”, en el que afirma: "La memoria, o mejor, el recuerdo, y su sostén, el tiempo: la percepción sensorial y las falacias de la representación; la ceguera (la ilusión de totalidad) y el ver (los fragmentos, las manchas): pasos de una escritura que despliega la historia de su opresión, de su incomodidad, y que se niega a proponer en la narración [...] ningún triunfo, ningún reino, más allá de sí misma" ${ }^{8}$ A las falacias de la representación, Gramuglio opone un triunfo de la escritura. Por su parte, Beatriz Sarlo, define la producción de Saer como "...una obra que nunca ha desmentido su radicalidad estética y cuya perfección se funda en la coherencia de la experimentación narrativa". ${ }^{9}$ Las citas, que funcionan apenas a modo de ejemplo y podrían multiplicarse, permiten entrever que la afectación, la ridiculez y la lejanía que diagnostica Gambarotta pueden ser atribuibles a las cualidades literarias de Saer, como si en lugar de ver allí una escritura de calidad indiscutible, observara una suerte de "exceso de literatura".

Aceptemos por el momento esta hipótesis, pues ella nos permitirá señalar que ese "exceso de literatura" no conduce a Gambarotta a una escritura realista, o descuidada, sino, y aquí me adelanto al hilo de mi argumentación, al "fracaso" de un poeta como Juan Desiderio y a su "zanjita". En efecto, como contraposición a Glosa, Gambarotta, en la charla mencionada, se refiere al poemario La zanjita de Juan Desiderio:

Es un texto jugado al fracaso, al punto que las "y" suplantan a las "ll". A mí me pareció magistral la lectura de Desiderio, como si estuviera viendo a Hendrix en 1967, antes de que lo hubieran descubierto otros. ${ }^{10}$

La simpatía por el fracaso, confío, reafirma la hipótesis propuesta en el párrafo anterior. El nombre del músico Jimi Hendrix $^{11}$, y teniendo en cuenta que Gambarotta menciona la lectura de Desiderio, debe entenderse en relación a sus performances frecuentemente escandalosas sobre el escenario, pero además supone la decisión explícita de traer a un universo de referencias literarias, de alta literatura - con lo cual estaríamos en un terreno saeriano -, una referencia proveniente del rock. ${ }^{12}$

Pero Desiderio no es cualquier poeta y La zanjita no es cualquier libro. Frecuentemente se ha señalado que La zanjita, publicado en 1992, es un poemario central para la nueva poesía de los años noventa. El tratamiento del lenguaje oral, que esquiva lo meramente coloquial, su topografía barrial que re- 
mite al margen, a la pobreza y al joven lumpen, constituyen el puntapié inicial de una poesía argentina ${ }^{13}$ que encontraba otras escenografías y escuchaba otros lenguajes que dieran cuenta de una experiencia individual y social radicalmente diferente, tramada por el derrumbe del alfonsinismo, el ascenso del menenismo y un mundo que en el lapso de diez años parecía haber cambiado más que en los últimos doscientos.

En el segundo texto citado de Gramuglio se proponía la "zona” como una categoría conceptual y espacial para pensar la literatura de Saer, que de modo espiralado, a la Balzac, retomaba personajes, desarrollaba situaciones e iba construyendo una topografía litoraleña. Si esto fue pensable con Saer, me pregunto, porqué no pensar la "zanjita" como la zona desde donde estos jóvenes poetas comienzan a publicar a partir de los años noventa. Es desde la zanjita, así en “chiquito” porque lo otro sería "la gran literatura", desde donde debe terminar de comprenderse la apuesta por el fracaso de Gambarotta, pues desde allí y allí, no sólo hay un diccionario restringido sino también, como apunta Edgardo Dobry, "un discurso de la desilusión, deliberadamente manchado de barro y de grasa, cuando no de sangre, con algo de asco y de befa, con una absoluta falta de ilusiones". ${ }^{14}$ La zanjita como topos pone de manifiesto la necesidad de que lo político - y el desencanto que le fue inherente durante los años noventa - adquiera otro régimen de visibilidad y otros enunciados, menos afines al lujo léxico que podía expresar la prosa de Saer, y más propensos a escuchar los nuevos murmullos lúmpenes y las hilachas de un pasado que parecía extinguido. La zanjita es un topos, una ubicación desde la cual se obtiene una visión otra, porque como se dice en Punctum: "Enfocando una linterna desde el margen izquierdo / se obtienen sombras transversales en la escenografía" ${ }^{15}$.

Sin embargo, y contra la tentación del realismo, porque ni Desiderio ni Gambarotta quieren ser los nuevos representantes de Boedo, ni una remake de Juan Gelman, la zanjita pero también el punctum dicen al tiempo que callan, y cuando callan dicen: constituyen breves destellos discursivos que pugnan por devenir audibles en medio de la frase perfecta y el tornado neoliberal; son tajos que nos apuntan y despuntan. Recordemos, en este sentido, el comienzo de La zanjita: Meté la mano / sacá lo hueso de poyo / de la zanja / meté la mano / te cortaste lo dedo / por sacar la mitá / de lo cien peso / de la tierra / y sus tendones / se vieron hermosos / bajo el sol”16. Desde esta doble perspectiva, que en el poemario de Gambarotta entreteje poesía e historia política, cadáveres y traumas, quisiera proponer a continuación algunas reflexiones sobre Punctum. tuación de Walker Brothers, Engelbert Humperdinck y Cat Stevens; cerraba The Jimi Hendrix Experience. Un elenco de talentos realmente incoherente. Mientras el segundo single, 'Purple haze', publicado con la compañía discográfica de Kit Lambert, Track Records, entra rapidamente en las listas de éxitos, Jimi Hendrix aparece en la primera página de todos los periódicos cuando, al final del primer concierto, prende fuego a la guitarra. El espectáculo es calificado de obsceno y de socialmente peligroso, por lo que Hendrix es invitado repetidamente a moderar los tonos más agresivos. Al final de la gira, Hendrix se ha convertido en un personaje de gran popularidad.

\section{Fabián Casas realiza algo} similar en su cuento "Casa con diez pinos" (escrito aproximadamente en 2001), en donde el personaje parodiado es Juan José Saer. El título del cuento remite a una canción del grupo de rock argentino Manal. Y en un momento se dice lo siguiente: "El Gran Escritor se quedó rumiando algo. Entonces, como si fuera un médium en trance, me empezó a dictar el super canon: Borges, Macedonio, Juan L. Ortiz, Faulkner, Onetti, Musil, Joyce, Kafka. Me parecía estar en la cancha escuchando a La voz del Estadio pasar la formación de un equipo de muertos. Cuando el listado pareció llegar a su fin, yo, tímidamente, le pregunté si le gustaba Ricardo Zelarayán. “¿Zelarayán?” me dijo. “¿Es un escritor argentino?”. Le dije que sí. Se quedó pensativo un rato largo, mirando la mesa, la tacita blanca de café. Era Anatoli Karpov pensando qué pieza mover. Después agachó el mentón, se durmió, roncó, pedorreó", Los lemmings, 2005, p. 45.

13. A los nombres de Desiderio, Rubio y Gambarotta se pueden sumar los Daniel Durand, Laura Wittner, Carlos Batilana, Fabián Casas.

14. DOBRY, Edgardo. "Poesía argentina actual: del neo-barroco al objetivismo. (y más allá)", 2006, p. 132-3. 
15. GAMBAROTTA, Martín. Punctum, 2011, p. 90. Desde ahora, todas las citas de Punctum se harán en el cuerpo del texto con los números de página entre paréntesis.

16. DESIDERIO, Juan. $L a$ zanjita, 2001, p. 7.

17. RANCIÈRE, Jacques. El destino de las imágenes, 2011, p. 26.

\section{Ver y oír desde la zanja}

Compuesto por treinta y nueve partes, Punctum es un poemario antilírico protagonizado por una serie personajes o un mismo personaje desdoblado: Guasuncho, Cadáver, Gamboa, Confuncio. Él o ellos deambulan por los márgenes de Buenos Aires, en ciudades del conurbano bonaerense como Gerli o Hurlingham, o en pequeñas ciudades de provincia como Concordia. A él o a ellos les gusta la música punk, el heavy metal, el trash; él o ellos se declaran futboleros. En destartalados televisores él o ellos miran viejas series: Bonanza o Kojac; duermen sobre colchones tirados en el suelo. Parecen afásicos, con problemas para nombrar o recordar, o aún leer. No esperan demasiado, no entienden demasiado, se aferran, cuando pueden, a los objetos que los rodean.

En esa deriva, intermitentes, asoman dos períodos históricos concretos de la historia argentina: los años setenta, a través de una serie de referencias a las organizaciones armadas y a las organizaciones sindicales peronistas; y los años noventa que, sin ser mencionados de modo explícito, resuenan en las imágenes desoladas, en los paisajes miserables, en la trama de una industria devastada. Pero Punctum, lejos de ofrecernos imágenes reconocibles, es una operación sobre la lengua que se presenta como desmontaje, y una sucesión de encabalgamientos que quiebran el sentido o presentan el sentido y la historia - la de los setenta, la de los noventa - como resto apenas audible, como ruina.

Quisiera detenerme en primer lugar en la operación de desmontaje y describir algunos de sus efectos. Muchos de los versos que componen Punctum nos inducen a pensar que estamos en presencia de un verso depurado, en donde un objeto emerge con nitidez. Doy algunos ejemplos "heladeras en desuso / dejadas al fondo del baldío, unos hombres / colocando balizas / que van a titilar de noche alrededor de un pozo" ( $\mathrm{p}$. 37); o "Vienen amigos noctámbulos con camperas, / tienen escudos de STP bordados en las mangas, / apagan cigarrillos en las plantas” (p. 55). Pareciera ser que estamos ante una escritura apegada al objeto, sin metáforas (y en este sentido, es el modo en que Gambarotta enuncia el fracaso de la literatura). La nitidez producida por el desmontaje, sin embargo, no debe entenderse como transparencia o simplicidad. La fragmentación es, como afirma Ana Porrúa, la textura de Punctum. Las imágenes de Gambarotta no son únicamente heladeras, terrenos baldíos y balizas, "son operaciones que enlazan y desvinculan lo visible y su significación [...] que producen y desvían las expectativas" 17 porque emergen en el marco de una narración cuya signatura es el corte. 
Por otra parte, la operación de desmontaje posee un suplemento que contribuye al desconcierto que parece atravesar todo el poemario. Resultado de una afasia que invade por momentos al o a los personajes, los objetos pierden su nombre: "Cómo se llama eso que cuelga de la pared, / cómo se llama eso que cubre la lámpara / Rodeado de cosas sin nombre...” (p. 10 ), en uno de esos tantos momentos de pérdida. Y junto con la afasia - una forma del olvido - "el" o "los personajes" también padecen una suerte de dislexia visual, "No lee, Confuncio, / en el tablero que anuncia / la partida de los servicios / Diamante sino Daimante, / no Bahía Blanca sino Bhaía Bancla. / Tiene problemas para entender / los números que informan / el horario de salida de los micros” (pp. 39-40).

En los versos de Punctum la lengua aparece de dos maneras: con una naturalidad que en verdad debe ser leída como radical desnaturalización, y como una lengua impotente para capturar la materia del mundo - otro fracaso de la literatura. El o los personajes de Punctum, que suelen presentarse en estado de somnolencia ${ }^{18}$, no controlan la lengua que los habita, que los confunde, que los sume en la penumbra. Este caos producido por el desmontaje, la afasia y la dislexia, es, por un lado, la forma en la que se abre paso una memoria - una forma de la escucha por el olvido u olvido tramado por una memoria, o simplemente una escucha descontrolada y afásica - "el nombre innombrable que toman los hechos / pasados haciendo eco en el presente" (p. 39), y que induce al sueño en plena vigilia porque todo parece haber sido pacificado,

pacificados, los músculos de la cara:

pacificados. Las fundiciones de acero: pacificadas; los Altos Hornos Zapla:

pacificados; en paz descansan las perforadoras (p. 49).

Y por el otro, ese caos es el presente de una lengua replegada por las desventuras de una democracia traicionada. Observemos un ejemplo en este segundo sentido. Se dice en la primera parte de Punctum, "mira la foto de una amiga / que estuvo internada / en un hospicio de París. Eso / suena pretencioso y, releyendo, / sería mejor cambiar París por Federación, hospicio / por hospital, internada por encerrada..." (p. 15). La sustitución aquí, puede pensarse, funciona al servicio del desmontaje, pero de un desmontaje literario si se quiere: se sustituye esa ciudad literaria -París, patria de Saer- por una pequeña ciudad de la provincia de Entre Ríos -Federación-, se sustituye la palabra "hospicio" por el más oral "hospital". Sin embargo, París por Federación y hospicio por hospital no son simples sustituciones léxicas, son sustituciones a la vez literarias y sociales, que remiten a un margen social: no se va a París,
18. Así comienza: "Una pieza / donde el espacio del techo es igual / al del piso que a su vez es igual / al de cada una de las cuatro paredes / que delimitan un lugar sobre la calle. / La bruma se traslada a su mente / vacía, no sabe quién es....” (p. 9). 
19. Y unos pocos versos más abajo no será la UOM (que significa la Unión Obrera Metalúrgica, que remite a Rucci y al Perón de la Plaza del 1ero de Mayo), sino, la U / O / M, que se rompe en una letra para cada verso.

20. En este sentido llama la atención la abundancia de referencia al óxido, metáfora de la ruína en su asociación con la historia moderna, a lo largo del poemario. Doy tres ejemplos: "Las manchas de óxido en el cielo- / el color de la luz sobre las cosas, el cielo que se retrae y es óxido borroneado / entre sus ojos y cae dormido de nuevo, pero aparece / un orden en la materia despierta." (p. 9); "En el sentido estricto,/ ninguna, a no ser / nada, separa esa noche / de las manchas de óxido / que se despliegan hoy" (p. 21); "si lo que seguía al trueno era relámpago, / o, a decir verdad, viceversa; lo que parecía / ser, lo que sin lugar a duda era, lo que empezó / siendo una mancha de óxido en el cielo" (p. 66). se va a Federación o también a Bahía Blanca o al Barrio Pepsi o a Ciudad Evita; no se interna en un hospicio, se encierra en un hospital, seguramente público, seguramente desmantelado.

En segundo lugar, y como apunté anteriormente, en Punctum hay una política del corte, con encabalgamientos brutales, y la presencia enfática de puntos suspensivos y líneas entre los versos, lo que debilita toda marca contextual y toda certeza. En ese marco, no sólo se debe hablar de una política del corte, sino de la historia política como corte. Es decir, no se trata de reponer aquello que está omitido, ya sea en relación a la historia política, ya sea en relación al presente, pues el fragmento no tiene una función alegórica, es significativo en sí mismo, resto encriptado de un habla muerta. Voy a detenerme en una serie de versos para ejemplificar lo que acabo de sostener:
No soy yo
el que se lleva el tenedor con una papa hervida a la boca un tanto fosforescente contra
la ondulación de la hornalla:
es Hielo, que a los 15 andaba con un brazalete celeste y blanco con un 6 y un 2
impreso en una tipografía pesada, oscura.
Cada primero de Mayo, Hielo era de la banda
que le daba a los de la orga para que tengan pero
después de un par de lecturas se abrió de la derecha
y se pasó a la 7 de Mayo
para finalmente abandonar y dedicarse. (p. 45)

Como se puede apreciar, la serie de versos está toda encabalgada, pero el último verso, que esperamos que se encabalgue en el verso siguiente, cierra con un punto. Ese verso, como oración aislada, es gramaticalmente incorrecto porque el verbo "dedicarse" requiere un complemento. Es decir, el punto corta el sentido. Asimismo, en los versos citados hay informaciones que remiten a la historia política de Argentina, el "un 6 y un 2 ", alude a las 62 organizaciones peronistas, "la orga" alude a la organización armada Montoneros, "la 7 de Mayo" es una agrupación de izquierda. Sabemos, al menos lo saben los argentinos de cierta edad, que los versos hablan del peronismo, de las diferentes tendencias peronistas que tuvieron una fuerte presencia durante los años setenta; sabemos que esas siglas corresponden a la derecha y a la izquierda peronista. Pero que los versos aludan a todo ello ¿qué significa?, ¿hay allí un sentido a desentrañar?, ¿se nos niega el sentido en el punto que clausura el verbo "dedicarse", pero aparece en estas referencias? Entiendo que no, esas referencias, cortadas, pues no son las 62, sino un 6 y un 2; no son los montoneros, sino la "orga", no son la agrupación 7 de Mayo, sino "la 7 de Mayo"19 más que citas o alusiones, son, efectivamente, fragmentos, y el pasado que traen consigo adviene roto, quebrado, arruinado. ${ }^{20}$ 


\section{El show de los muertos}

El título del libro, Punctum, que remite a la categoría que Roland Barthes postula para las imágenes fotográficas en su libro La cámara lúcida, puede aportar mayor claridad a lo expresado en los párrafos anteriores. La definición del punctum que nos ofrece Barthes dice lo siguiente: "es ese azar que en ella me despunta (pero que también me lastima, me punza)"21. Es decir, habría en la imagen algo irreductible que la subjetividad no es capaz de decodificar, que en verdad la pone en crisis. Junto al punctum, que no toda fotografía contiene, Barthes propone el studium, del que dice: "por medio del studium me intereso por muchas fotografías, ya sea porque las recibo como testimonios políticos, ya sea porque las saboreo como cuadros históricos”22. El studium, por el contrario, funciona como información, como relato histórico, como aquello que es transmisible. Con el studium aprendo, con el punctum desaprendo.

Algunas cuestiones que en verdad son una disgresión antes de llegar al punto (o al punctum). Resulta interesante destacar, como se desprende de la cita anterior, que Barthes coloca el "testimonio político" del lado del studium, y hasta es capaz de afirmar lo siguiente:

Hojeaba una revista ilustrada. Una foto me detuvo. Nada extraordinario: la trivialidad (fotográfica) de una insurrección en Nicaragua: una calle en ruinas, dos soldados con casco patrullan; en segundo plano pasan dos monjas. ¿Me gustaba la foto? ¿Me interesaba? ¿Me intrigaba? Ni tan sólo eso. Simplemente existía (para mí). ${ }^{23}$

No se pretende aquí que Barthes se interese por una insurrección en Nicaragua, pero sí se advierte que el studium lo deja indiferente, que ocupa un lugar subalterno en su valoración, que lo que realmente le interesa detectar, en cada imagen, es el punctum ${ }^{24}$.

Entonces cómo pensar el título del poemario de Gambarotta, que no deja de lado la historia política reciente de la Argentina, pero que nos direcciona de inmediato a la categoría que Barthes propuso, si el propio Barthes coloca a la política -la revolución en Nicaragua es un ejemplo aunque hay otros- del lado del studium. En verdad, creo que el punctum de Gambarotta se aproxima a la relectura que, vía $\operatorname{Lacan}^{25}$, realiza Hal Foster en El retorno de lo real, y por medio del cual propone la categoría de "realismo traumático" para pensar la producción -un momento de ella- de un artista como Andy Warhol. Pero si Gambarotta reconfigura esa categoría, si dota, en definitiva, de politicidad a lo real, no por ello Barthes debe
21. BARTHES, Roland. La cámara lúcida, 2009, p. 65.

22. Ibidem, p. 64

23. Ibidem, p. 53-54.

24. En El destino de las imágenes, Jacques Rancière realiza una crítica a la división propuesta por Barthes. Sostiene, refiriéndose al sentido que Barthes le otorga al punctum: "Es poco probable que el autor de las Mitologías haya creído en la fantasmagoría paracientífica que convierte a la fotografía en una emanación directa del cuerpo expuesto. Es más verosímil que este mito le haya servido para expiar el pecado del mitólogo de ayer: a saber, el de haber querido quitarle al mundo visible sus prestigios, de haber transformado sus espectáculos y placeres en un gran tejido de síntomas y en un turbio intercambio de signos. [Por ello] inclina la balanza en la otra dirección al valorizar, en nombre del punctum, la evidencia explícita de la fotografía para rechazar en la banalidad del studium el desciframiento de los mensajes" (2011, p. 31-32).

25. En verdad, Barthes también desarrolla esta categoría a partir de Lacan, igual que la categoría de goce en El placer del texto. 
26. BARTHES, Roland. $L a$ cámara lúcida, 2009, p. 39. ser desplazado al cuarto de los trastos viejos. La triada que propone en el apartado cuarto de La cámara lúcida es un buen complemento para pensar la idea de retorno traumático, que es lo que en definitiva propone Hal Foster, y es la materia que compone Punctum -materia que permite el cruce entre historia y poesía. En dicho libro, Barthes propone una división entre el Operator, el Spectator y el Spectrum, y afirma de esta última categoría, que es la que me interesa: "esta palabra mantiene a través de su raíz una relación con 'espectáculo' y le añade ese algo terrible que hay en toda fotografía: el retorno de lo muerto". ${ }^{26}$

El Punctum de Gambarotta nos habla del retorno de un susurro traumático, el susurro de una historia que se resiste a ser "enterrada", un susurro que como pulsión insiste e inscribe los setenta en los noventa mediante estilemas y fragmentos. Retorno de lo muerto, o para estar en sintonía con el poemario, retorno de un régimen del cadáver que congrega tanto a los muertos políticos, que insisten en regresar, o que son convocados,

por Julio Troxler, gritaban presente por Paco Urondo presente por Felipe Vallese presente por la 7 de mayo Gamboa, basta, este es un amanecer patético en Concordia, Entre Ríos, 1991 (82);

como al personaje o los personajes que deambula/n por el poema en un ir y venir que siempre queda a mitad de camino:

\footnotetext{
Recién cuando Kwan-fu-tzu anda bordeando el río se encuentra a Confuncio, que se quedó sin cigarrillos antes de entrar a la terminal y las dos partes se vuelven a juntar y son de nuevo Confuncio, indivisible, que no puede decidir, iluminado por el único foco del micro, cuál de los dos tomar (p. 39).
}

Son esos retornos, arruinados, fragmentarios, en suma, traumáticos, los que convierten a Punctum en un texto hablado por ese pasado militante de los setenta, que sin embargo no consigue dotarse de sentido, y por un presente en penumbras, cubierto por el óxido y la basura de una sociedad postindustrial. Por ello, resulta difícil escuchar en Punctum herencias o débiles mesianismos más bien, y cierro con Gambarotta, lo que encontramos y lo que escuchamos es "una paz / gelatinosa en un estado en bancarrota” (p. 93). 


\section{Referencias}

BARTHES, Roland. El placer del texto. Lección inaugural. Buenos Aires: Siglo XXI, 2008.

. La cámara lúcida. Buenos Aires: Paidos, 2009.

CASAS, Fabián. Los lemmings. Buenos Aires: Santiago Arcos editor, 2005.

DESIDERIO, Juan. La zanjita. Buenos Aires: Ediciones

Deldiego, 2001.

DOBRY, Edgardo. Poesía argentina actual: del neo-barroco al objetivismo. (y más allá). In:

FONDEBRIDER, Jorge (comp.). Tres décadas de poesía argentina. Buenos Aires: Eudeba, 2006.

FOSTER, Hal. El retorno de lo real. Madrid: Akal, 2001.

GAMBAROTTA, Martín. El habla como materia prima. In: FONDEBRIDER, Jorge (comp.). Tres décadas de poesía argentina. Buenos Aires: Eudeba, 2006.

. Punctum. Buenos Aires: Mansalva, 2011.

GRAMUGLIO, María Teresa. Las aventuras del orden, In: Los libros $\mathrm{n}^{\mathrm{a}}$ 3, Buenos Aires, septiembre 1969.

- Juan José Saer: el arte de narrar. In: Punto de Vista n⿳a 6 ,

Buenos Aires, mayo 1977.

. La filosofía en el relato. Sobre 'El entenado' de Juan

José Saer. In: Punto de Vista nª 20, Buenos Aires, mayo 1984.

PRIETO, Martin. Breve historia de la literatura argentina.

Buenos Aires: Taurus, 2006.

RANCIÈRE, Jacques. El destino de las imágenes. Buenos

Aires: Manantial, 2011.

SAER, Juan José. Glosa. Buenos Aires: Seix Barral, 1995.

SARLO, Beatriz. La condición mortal. In: Punto de Vista n ${ }^{\underline{a}}$ 46, Buenos Aires, agosto 1993. 
